\title{
Brick Kilns of Nepal: A Non-Governmental Organization Perspective
}

\author{
Shilpa Shrestha, Steven M. Thygerson* \\ Department of Public Health, College of Life Sciences, Brigham Young University, Provo, UT, United States \\ Email: *steven.thygerson@byu.edu
}

How to cite this paper: Shrestha, S. and Thygerson, S.M. (2019) Brick Kilns of Nepal: A Non-Governmental Organization Perspective. Open Journal of Safety Science and Technology, 9, 1-6.

https://doi.org/10.4236/ojsst.2019.91001

Received: December 19, 2018

Accepted: January 29, 2019

Published: February 1, 2019

Copyright (๑) 2019 by author(s) and Scientific Research Publishing Inc. This work is licensed under the Creative Commons Attribution International License (CC BY 4.0).

http://creativecommons.org/licenses/by/4.0/

\section{(c) (i) Open Access}

\begin{abstract}
Better Brick Nepal (BBN) works under the larger NGO, Global Fairness Initiatives, to promote the reliably sourced brick manufacturing by eliminating forced, bonded labor, and child labor, promoting workplace safety and health, providing fair wages, and preventing workplace harassment. The brick industry is regarded as the second largest source for air pollution after vehicle emissions in Kathmandu Valley. The brick kiln workers who live on the kiln premises in huts are highly exposed to both indoor and outdoor air pollution. This study reviewed the practices of BBN kilns that adhere to recommended standards for worker rights, health and safety. An NGO such as BBN is proving successful at eliminating inhumane work practices and in improving brick kiln worker health and safety.
\end{abstract}

\section{Keywords}

Brick Kiln, Air Pollution, Public Health, Child Labor

\section{Introduction}

Brick is a chief building material used in Nepal. Bricks are made of clay as it is the most abundant source of potential brick materials [1]. A mixture of inorganic compounds like free silica, iron oxide, lime, magnesium carbonate, alkalis, calcium carbonate, calcium sulfate, sodium chloride and varying amounts of organic materials is found in clay dust. The burning of biomass fuels in clay dust increases exposure to gases including sulfur dioxide, hydrogen sulfide, carbon dioxide and carbon monoxide and particulate air pollutants [2].

In developing countries, brick manufacturing is a small-scale and unorganized industry concentrated mainly in the rural and suburban areas (see Figure 1). The brick industry is rapidly developing to meet the increasing demand for bricks in new construction [3]. Due to increased urbanization and the April 2015 


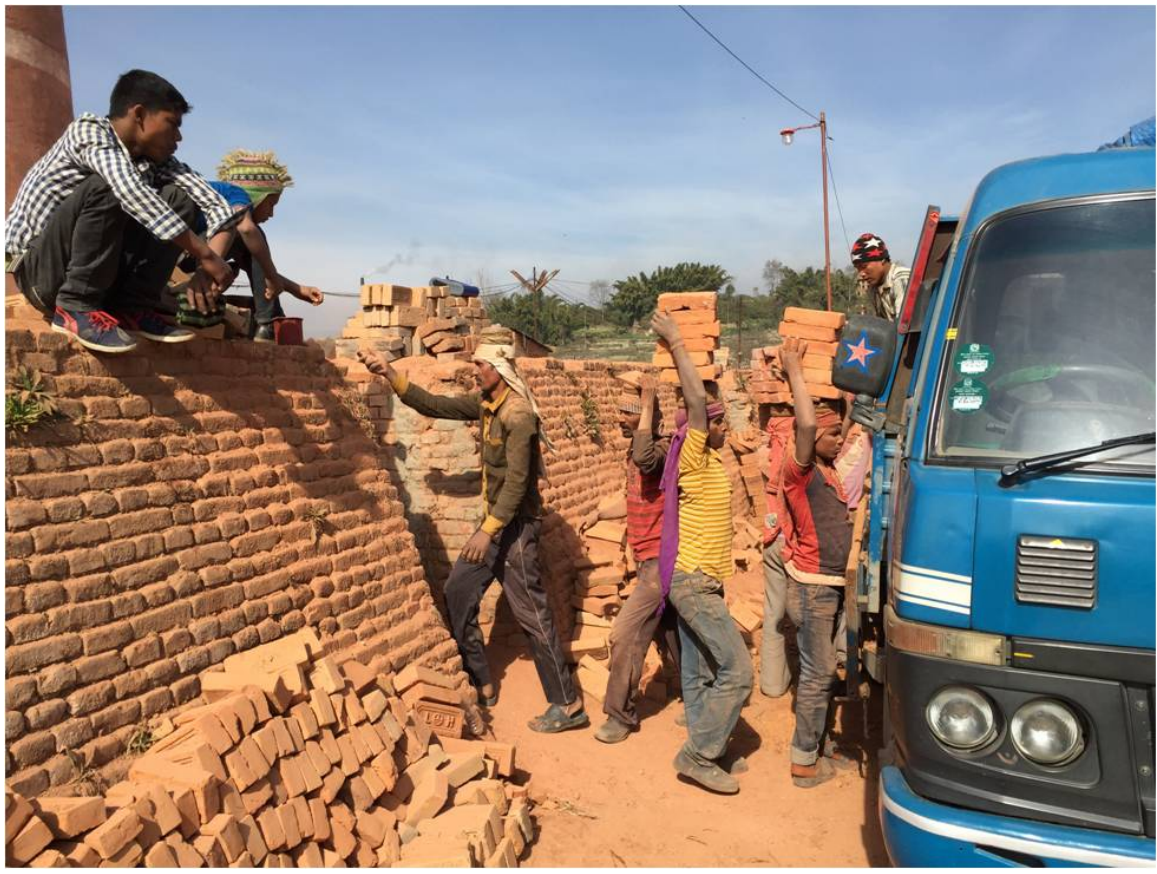

Figure 1. Workers carrying fired bricks. Figure by Steven Thygerson.

earthquake in Nepal, the rate of construction and the demand for bricks are increasing substantially [1]. It is estimated that 1294 brick kilns are currently legally functioning in Nepal [4]. In Kathmandu Valley, the brick industry is regarded as the second largest source for air pollution after vehicle emissions. A previous study found that air concentrations of particulate matter were much higher during the brick-making season compared to the rainy season [5]. These pollutants are produced as a result of incomplete combustion of fuel and are also present in coal dust, ash present in coal, and burned clay particles. The fine solid or liquid particles scatter throughout the air. Along with the rise in particulate matter air concentrations around the brick kiln is an increasing number of community members diagnosed with asthma [6].

Besides exposure to air pollutants generated by burning of fuel during the baking process of bricks, the workers and their families are also exposed to the indoor air pollution. The majority of the workers at the brick kilns migrate from their home village to the brick kilns. Most of the migrant workers are farmers who migrate to the brick kilns for work once the harvest season concludes. They live inside the kilns' premises in single roomed, small huts made of bricks. They prepare meals inside the huts using traditional cook stoves. Firewood is the main source of fuel for traditional cook stoves. The huts have no proper ventilation systems (e.g. chimneys). Therefore, people live inside the huts, including children, and inhale the pollutant gases. Cigarette smoking is also prevalent. Outdoor air pollution, indoor air pollution, and cigarette smoke increase their risk for respiratory problems like COPD, lung cancer, and silicosis.

Better Brick Nepal (BBN) is a non-governmental organization in Nepal working under an international non-governmental organization called Global 
Fairness Initiatives (GFI). GFI works at the local level to enhance the local economy that works for local stakeholders rather than making local stakeholders work for a global economy. It engages the government to develop innovative public policy interventions to support and create economic opportunities for the poor working people. It also builds the workforce capacity by engaging local unions and other organized formal and informal worker groups. GFI improves the access of local products to the market by working with private sector leaders and multiple stakeholders. It brings fairness to free trade by including stakeholders that have been excluded historically. BBN works to improve brick kiln workers' rights, health and safety by following the five aforementioned standards. The goal is to: 1) eliminate forced and bonded labor, 2) eliminate child labor, 3) improve workplace safety and health, 4) ensure owners provide fair wages, and 5) eliminate workplace harassment. It currently has 43 brick kilns following its recommended work practices in Nepal.

The three objectives of this study were to 1) collect indoor and outdoor air samples for air pollution and other brick kiln air contaminants, 2) informally observe work behavior and practices in regard to health, forced labor, and safety, and 3) describe how a non-governmental organization called Better Brick Nepal $(\mathrm{BBN})$ is working to improve work practices and conditions for the brick kiln workers. These last two objectives are described herein.

\section{Methods}

Four different non-BBN brick kilns located inside Kathmandu Valley were selected for our visits. At each kiln, we informally observed work behavior and practices as well as living conditions of workers at four different huts (i.e. 16 huts total) located inside each kiln's premises. The huts closest to the brick kiln housed the fire masters, and the huts surrounding the perimeter of the kilns were brick carrier's huts. Air samples in those 16 huts were collected for carbon dioxide, carbon monoxide, sulfur oxide, nitrogen oxide, silica, and $\mathrm{PM}_{2.5}$. We also visited two of the $\mathrm{BBN}$ associated brick kilns to compare the work behavior and practices. In-person interviews were conducted with the kiln owner, worker, worker committee member, compliance officer, and grievance officer of the BBN kiln to determine compliance up with the five standards of BBN.

\section{Results}

We observed child labor in some of the non-BBN kilns working as red brick carriers and coal carriers. The workers in those brick kiln had no fixed working hours. Though specific working hours were not specified, they reported working from dawn to dusk. They were paid based on the number of bricks they made or number of bricks they carried. No health facilities were provided for the workers. These kilns did not have automation or machinery, so they depended on the physical strength of the workers. None of the workers were trained in brick making, brick carrying, or safe work practices. The majority of workers wore sandals (flip flops) instead of true foot protection. Many fire masters fed the coal 
into the fire pit with their bare hands. Contrary to non-BBN kilns, in BBN kilns, no child labor, forced or bonded labor was observed. All personnel interviewed at the BBN kilns were aware of the five standards of BBN. The workers had received training regarding those standards. We observed that the BBN kilns were mechanized and used improved technology in the kiln which reduced the air pollution in the environment. The results of the air samples will be demonstrated in another forthcoming article.

\section{Discussion}

Benefits such as health care, paid leave, free lunch, and bonus in monetary form were reasons for increased worker retention to those particular BBN kilns. When asked about occupational safety in their working environment, the workers reported they feel safe at the work place. From the survey, it was clear that the BBN associated kilns were working hard on keeping up with the five principles of BBN. To eliminate forced and bonded labor, BBN makes sure the naike (middleman) is not involved during the hiring process. The industries are not allowed to keep any kind of original documents like the citizenship of the worker. The companies also need to have fixed working hours for all laborers. To eliminate child labor, BBN makes sure that the kiln does not hire anyone less than 18 years of age. Legal action will be taken against the kiln if children are.

To promote workplace safety and health, BBN started training the workers to create awareness among them regarding brick kiln hazards. Different kinds of personal protective equipment (PPE) such as dust masks, boots, goggles, gloves, and hard hats were provided to the workers depending on the demand and type of work. BBN provides PPE to workers during each training session. To provide fair wages to the workers, BBN makes the companies pay via a salary system rather than the piece rate system. All transactions must be clear to the worker. This protects the workers from being deceived by the kiln owners or the middleman. Having the original document like citizenship card, birth certificate, or migration certificate with the workers gives them a sense of freedom and security. It makes them more independent.

Mechanized work systems produce bricks faster and eliminate many of the musculoskeletal injuries so prevalent in the brick industry. BBN kilns have a higher proportion of brick makes by these types of systems. BBN kilns provide initial and on-going safety training regarding the prevention of workplace injury. This motivates workers and owners to also see the benefit of reduced workplace injury costs. Forced and bonded labor causes extreme health inequalities. People in more vulnerable circumstances such as children, women, undocumented migrants, and people living in poverty are disproportionately affected [7]. At the heart of forced and bonded labor is exploitation. This exploitation is made up of different forms of abuse such as serious occupational hazards, extensive hours, and poor pay. A systematic review on forced labor and health found that victims experienced multiple forms of abuse, numerous occupational hazards specific to the sector, and dangerous or unsanitary living conditions [8]. 


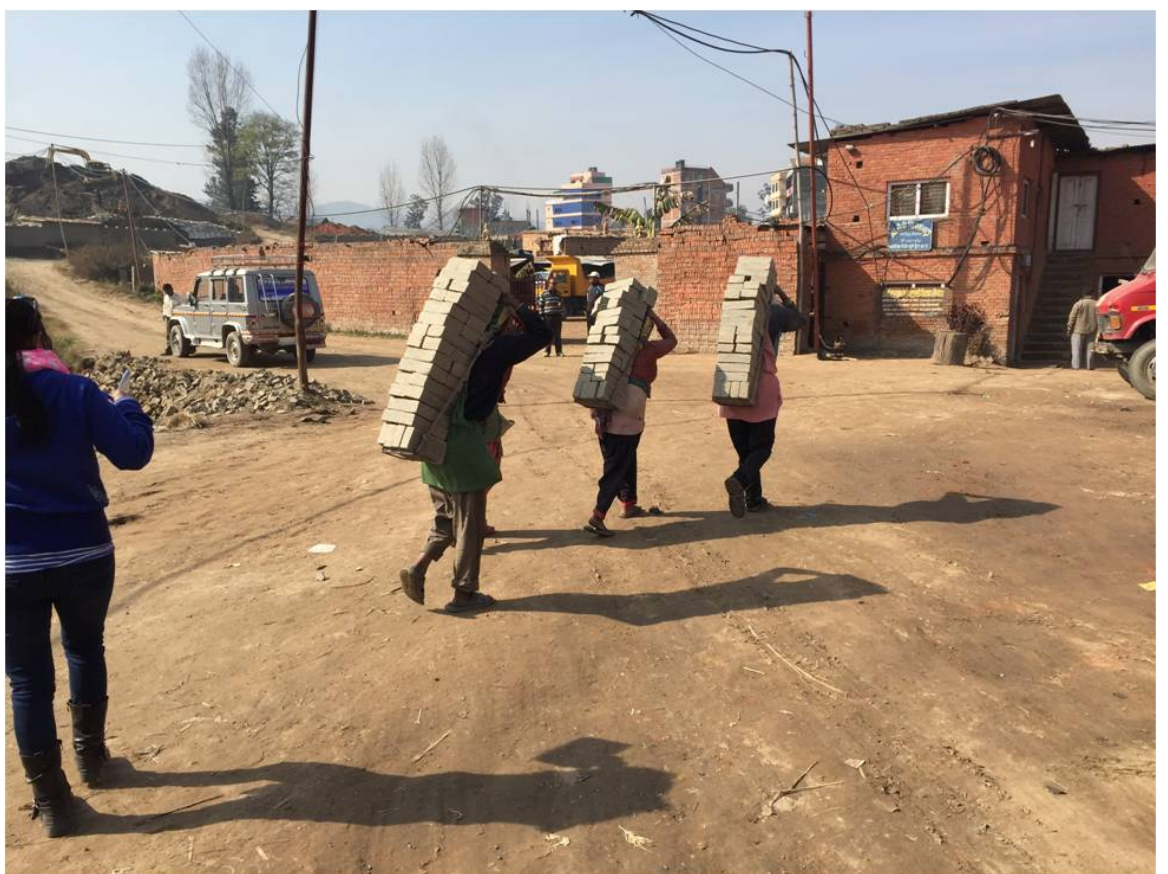

Figure 2. Workers carrying green bricks. Figure by Steven Thygerson.

Physically demanding forced labor with long working hours results in high incidence of physical injury [9]. Individuals who are bonded or forced to work in brick kilns may be exposed to various hazards including dust, heat, excessive weight, repetitive movements, etc. [6] (see Figure 2).

No forced and bonded labor means they are humanely and respectfully treated. The workers' voice is heard by the owners or people in power. As a result of action taken by brick owners and kiln workers, BBN kilns operate schools for the children of the parents who work at those kilns. This program has proven successful to reduce child labor at BBN kilns. According to the BBN annual report, the organization has made available 81 million child labor free bricks and overall 199 million bricks from the Better Brick Member kilns in 2016-2017 [4].

\section{Conflicts of Interest}

The authors declare no conflicts of interest regarding the publication of this paper.

\section{References}

[1] Health Research and Social Development Forum (2016) Brick Kilns in Nepal-A Situational Report.

[2] Shaikh, S., Nafees, A.A., Khetpal, V., Jamali, A.A., Arain, A.M. and Yousuf, A. (2012) Respiratory Symptoms and Illnesses among Brick Kiln Workers: A Cross Sectional Study from Rural Districts of Pakistan. BMC Public Health, 12, 999. https://doi.org/10.1186/1471-2458-12-999

[3] Singh, A.L. and Asgher, M.S. (2005) Impact of Brick Kilns on Land Use/Landcover Changes around Aligarh City, India. Habitat International, 29, 591-602. 
https://doi.org/10.1016/j.habitatint.2004.04.010

[4] (2017) Global Fairness Initiative Nepal-Annual Report 2016-2017. Global Fairness Initiative Nepal. http://globalfairness.org/images/gfinepalannualreport.pdf

[5] Raut, A. (2003) Brick Kilns in Kathmandu Valley: Current Status, Environmental Impacts and Future Options. Himalayan Journal of Sciences, 1, 59-61. https://doi.org/10.3126/hjs.v1i1.189

[6] Thygerson, S., Sanjel, S. and Johnson, S. (2016) Occupational and Environmental Health Hazards in the Brick Manufacturing Industry in Kathmandu Valley, Nepal. Occupational Medicine \& Health Affairs, 4, 248. https://doi.org/10.4172/2329-6879.1000248

[7] Zimmerman, C. and Kiss, L. (2017) Human Trafficking and Exploitation: A Global Health Concern. PLoS Medicine, 14, e1002437. https://doi.org/10.1371/journal.pmed.1002437

[8] Ottisova, L., Hemmings, S., Howard, L.M., Zimmerman, C. and Oram, S. (2016) Prevalence and Risk of Violence and the Mental, Physical and Sexual Health Problems Associated with Human Trafficking: An Updated Systematic Review. Epidemiology and Psychiatric Sciences, 25, 317-341.

https://doi.org/10.1017/S2045796016000135

[9] Zimmerman, C., Kiss, L., Hossain, M. and Watts, C. (2009) Trafficking in Persons: A Health Concern? Ciencia \& Saude Coletiva, 14, 1029-1035.

https://doi.org/10.1590/S1413-81232009000400010 